\title{
Muscular Power and Endurance in Young Competitor and Recreational Fencers
}

\author{
Philippe Dedieu \\ IRFSS - PREFASS, Croix Rouge Française, Limoges, France
}

Email address:

philippe.dedieu@croix-rouge.fr

To cite this article:

Philippe Dedieu. Muscular Power and Endurance in Young Competitor and Recreational Fencers. American Journal of Sports Science. Vol. 3, No. 6, 2015, pp. 103-108. doi: 10.11648/j.ajss.20150306.11

\begin{abstract}
Fencing competition can be studied at two time levels relative to metabolic processes to generate ATP which express particularly muscular power and muscular endurance capacity. Whereas the aerobic process allows to compete all along competition, the phosphocreatine process allows to meet the immediate demands imposed by high - intensity skills. The aim of this study is to compare the relationship between both muscular power and muscular endurance capacity in young fencers involved or not in competition. Using field tests, muscular power and muscular endurance capacity were studied in two groups of sixteen young fencers respectively involved or not in competition. Blood lactate and heart rates were measured. Because of the duration and organization of fencing competitions, fencers need both muscular power and muscular endurance capacity to face respectively high - intensity and long - term energy. However, out of a competitive context, the relationship between both muscular power and muscular endurance capacity is not crucial.
\end{abstract}

Keywords: Fencing, Phosphocreatine Process, Aerobic Process, Field Test

\section{Introduction}

Two analysis levels allow to study metabolic demand in fencing competitions. At a macroscopic level, the duration of a national fencing competition can range from 6 to 9 hours per day during two days. This specificity puts demands on the aerobic process, particularly for those who compete to final bouts $[1,2]$. At a lower level, during a bout, from 3 to 9 minutes, fencers repeat defensive and offensive patterns with repetitive forward and backward motions with numerous changes of direction $[1,3]$. These displacements need short and frequent sequences of high intensity exercises putting high demand on the phosphocreatine process. These displacements are spaced by low intensity activity allowing recovery periods [3].

So, fencing is a combat sport in which metabolic capability to generate ATP for muscle contraction can be provided by both aerobic and phosphocreatine processes [3]. The aerobic process provides long - term energy by using oxygen. It is unable to produce ATP to meet the immediate demands imposed by high - intensity skills. The phosphocreatine process provides immediate energy without using oxygen for 6 to 8 seconds. Following Astrand et al. [4], aerobic and phosphocreatine processes are used together while performing sport skills. However, they are involved at different levels of the skill performance. Both aerobic and phosphocreatine systems seem to be an important determinant of performance while fencing.

When in competitions, fencers must keep intact their phosphocreatine system faculties to meet the challenges of final bouts. Otherwise, high intensity exercises require the glycolysis system which is the third process to provide the metabolic capacity to generate ATP for muscle activity [5]. This anaerobic process re - synthetizes ATP producing lactic acid. When the accumulation of lactic acid in muscle and blood reaches a very high level, fatigue will occur [4]. Competitor fencers need to avoid this process to diminish risks of muscular fatigue and a decrease in cognitive activity [6]. Indeed, as with any combat sport, fencers have to perform simultaneously a physical task with great physical exertion and perceptual or decisional tasks [7]. In the situation of playoff bouts, physical or cognitive fatigue could be a disadvantage.

Even though aerobic and phosphocreatine systems seem necessary to succeed, their combined association appears to be crucial in competition. The relationships between maximal strength and muscular endurance in fencers - which are the expression of these physiological processes - have to 
be specified in order to assess the consequences of practicing in competition as opposed to recreational practice. Therefore, our study aims to explore this relation and to search for a possible correlation between these two processes in young fencers involved in competition and in young recreational fencers.

\section{Methods}

This study was done in accordance with the Helsinki Declaration and has been approved by the local ethics committee.

\subsection{Participants}

Thirty two fencers (males; age: 15. $59 \pm 1.76$ years; weight: $60.53 \pm 9.01 \mathrm{~kg}$; height: $173.43 \pm 5.99 \mathrm{~cm}$ ) participated in the study. They had been fencing for over five years (7. $36 \pm 1.87$ years). They were all epée fencers. Sixteen of them were all regularly competing in fencing national competitions and sixteen were recreational fencers. They volunteered to participate in the study. Each subject's legally authorized representative has been informed on the experimentation and has signed an informed consent.

\subsection{Procedures and Data Processing}

Muscular power is the amount of work performed per unit of time. It is the expression of the anaerobic phosphocreatine system. It was measured with Sargent test [8]. This test allows an indirect measure of muscle power in the lower limbs. The subject is positioned from side - on, $30 \mathrm{~cm}$ in front of the vertical projection of a board. A ruler is fixed along the board. The ends of the fingers are placed in chalk. The arm on the side of the wall is lifted fully extended, heels on the ground. The end of the fingers prints a first brand (h0) on the board. Without taking momentum of the legs bent at a $30^{\circ}$ position, the subject jumps as high as possible. The extension arm prints a second brand on the board (h1).

Three trials are given for each subject. The best score is taken into account. From this score, extrapolated muscular power is obtained using the formula of Lewis [9]:

$\mathrm{P}=\sqrt{4.9} \times$ weight $\times \sqrt{\mathrm{h} 1-\mathrm{h} 0} \times 9.81$

(P in watts, weight in $\mathrm{kg}$, (h1 - h0) in $\mathrm{m}$ )

Aerobic endurance expresses capacity to use a set of percentage of $\mathrm{VO}_{2}$ max that can be endured as long as possible. It was determined by using track with classic Cooper test [10]. It was also determined with a specific Fencing Endurance Test (FET) [11]. These two tests were performed with a three - day interval. No aerobic endurance training was performed in between.

The Cooper test was chosen as aerobic reference. The participants ran the greatest distance possible within 12 minutes. $\mathrm{VO}_{2} \max$ was obtained using the formula:

$$
\mathrm{VO}_{2}=(22.351 \mathrm{x} \text { distance })-11.288
$$

In addition, the blood lactate concentration was analyzed before and after warm - up, at the end of each test and 15 minutes after the end of each test from $20 \mu$ capillary blood (Accutrend Plus, Roche Diagnostics Gmbh, Germany). The heart rate was also recorded (Suunto Memory Belt, Vantaa, Finland).

Following the procedures determined by Weichenberger et al. [11], the Fencing Endurance Test (FET) was conducted on a fencing ground over a distance of $7 \mathrm{~m}$. The fencers moved forward and backward using fencing - specific steps holding their weapon in front of the body in the usual position. A change of direction was carried out at 0 and at $7 \mathrm{~m}$. The athletes started at a speed of $3 \mathrm{~km} / \mathrm{h}$. With the aid of acoustic signals given by a computer and markings on the floor, the athletes could orient themselves regarding the predefined speed and the changes of direction. The speed was kept constant over a period of $3 \mathrm{~min}$ to ensure steady state conditions.

During the test, the speed was increased by $1 \mathrm{~km} / \mathrm{h}$ every 3 min up to exhaustion. The highest speed level attempted was recorded for every participant. It represents the highest endurance level. In addition, the blood lactate concentration was analyzed (Accutrend Plus, Roche Diagnostics Gmbh, Germany) and the heart rate was recorded (Suunto Memory Belt, Vantaa, Finland).

Suprailiac, subscapular, triceps and biceps skinfold thickness were assessed using Harpenden calipers. Body fat percentages were calculated from the mean of three readings per site according to the formula of Durnin and Rahaman [12].

\subsection{Statistical Analysis}

Means and standard deviations were calculated for all parameters for each participant. The Bravais - Pearson correlation coefficient was calculated between Muscular Power and $\mathrm{VO}_{2} \mathrm{max}$ and the highest heart rate frequency determined with Cooper Test and between Muscular Power and the highest speed level and the highest heart rate frequency determined with FET. Estimation accuracy was indicated with $95 \%$ confidence limits. The correlation was deemed certain when the absolute value of inferior confidence limit was higher than significant threshold determined with Bravais - Pearson statistical table [13].

The mean values were averaged and contrasted using a $t$ test (competitive $v s$ recreational).

The significance level was set at $p<0.05$.

\section{Results}

Individual anthropometric and expertise data do not differentiate the competitive and recreational groups (Table 1). However, recreational fencers present higher percentage of body fat index than the competitive one do (resp. 15. $50 \%$ $\pm 1.88 v$ s. $13.89 \% \pm 2.07 ; P=0.04$ ) (Table 2).

The latter present a higher muscular power than the recreational' group $(P=0.01)$, characterizing a better amount of muscular work performed per unit of time. This difference is $29.41 \%$ higher in competitive than in recreational group (Table 2). 
The results of Cooper test show that the competitive group presents a higher $\mathrm{VO}_{2}$ max than the recreational' one (resp. $49.14 \mathrm{ml} \cdot \mathrm{min}^{-1} \cdot \mathrm{kg}^{-1} \pm 6.04$ vs. $37.06 \mathrm{ml} \cdot \mathrm{min}^{-1} \cdot \mathrm{kg}^{-1} \pm 7.76 ; P$ $=0.01$ ) indicating a better endurance capability of competitive fencers (Table 2). Along this result, the mean value of maximal heart rates determined with Cooper test is significantly lower in the competitive group than in the recreational one (resp. 153. 00 b. $/ \min$ vs. 159.37 b. $/ \mathrm{min} ; P=0.03$ ) (Table 2).
Table 1. Characteristics of participants. Values are mean $( \pm S D)$.

\begin{tabular}{lll}
\hline & $\begin{array}{l}\text { Competitive Group } \\
(\mathbf{n = 1 6})\end{array}$ & $\begin{array}{l}\text { Recreational Group } \\
(\mathbf{n = 1 6})\end{array}$ \\
\hline Age (years) & $15.84 \pm 1.68$ & $15.34 \pm 1.74$ \\
Weight $(\mathrm{kg})$ & $60.40 \pm 7.95$ & $60.66 \pm 9.68$ \\
Height $(\mathrm{cm})$ & $174.40 \pm 4.73$ & $172.46 \pm 7.31$ \\
Experience (years) & $7.55 \pm 0.18$ & $7.17 \pm 0.15$ \\
\hline
\end{tabular}

Table 2. Mean ( \pm SD) of Body Fat Index, Muscular Power, VO ${ }_{2}$ max (Cooper test), Maximal Heart Rate (Cooper test), Blood Lactate (Cooper test), Maximal Heart Rate (FET), Blood Lactate (FET) and Maximal Speed (FET). (*: significant main effect between Competitive and Recreational Groups).

\begin{tabular}{|c|c|c|}
\hline & Competitive Group $(n=16)$ & Recreational Group $(n=16)$ \\
\hline Body fat index $(\%) *$ & $13.89 \pm 2.07$ & $15.50 \pm 1.88$ \\
\hline Muscular power (W) & $1009.63 \pm 188.02$ & $780.19 \pm 183.65$ \\
\hline VO2 max (Cooper test) $(\mathrm{ml} \cdot \mathrm{min}-1 \cdot \mathrm{kg}-1) *$ & $49.14 \pm 6.04$ & $37.06 \pm 7.76$ \\
\hline Maximal heart rate (Cooper test) (b. /min)* & $153.00 \pm 16.46$ & $159.37 \pm 18.44$ \\
\hline Blood Lactate (Cooper test) $(\mathrm{mmol} / 1)^{*}$ & $11.68 \pm 0.50$ & $12.45 \pm 0.54$ \\
\hline Maximal heart rate (FET) (b. /min) & $183.62 \pm 9.24$ & $183.94 \pm 18.33$ \\
\hline Blood Lactate $(\mathrm{FET})(\mathrm{mmol} / \mathrm{l}) *$ & $13.43 \pm 0.26$ & $12.78 \pm 0.51$ \\
\hline
\end{tabular}

(FET: Fencing Endurance Test)

However, if the mean value of maximal speed determined with the specific Fencing Endurance Test is higher in competitive' group (resp. 128. $11 \mathrm{~m} . \mathrm{min}^{-1}$ vs. $98.96 \mathrm{~m}$. min $\left.{ }^{-1} ; P=0.01\right)$, one cannot differentiate both competitive and recreational groups by the value of maximal heart rate (resp. 183. 62 b. $/ \mathrm{min} v s .183 .94$ b. $/ \mathrm{min} ; P=0.35$ ) (Table 2).

Moreover, if the mean value of blood lactate concentration after Cooper test is significantly lower in the competitive group than in the recreational one (resp. $11.68 \mathrm{mmol} / \mathrm{l} v \mathrm{~s} .12$. $46 \mathrm{mmol} / \mathrm{l} ; P=0$. 02), the mean value of blood lactate concentration after the specific Fencing Endurance Test is significantly higher in the competitive group than in the recreational one (resp. 13. $44 \mathrm{mmol} / \mathrm{l}$ vs. $12.78 \mathrm{mmol} / \mathrm{l} ; P=$ 0. 01) (Figure 1). However, 5 minutes after the end of Cooper test and 5 minutes after the end of specific FET test, the mean value of blood lactate concentration is significantly lower in the competitive group than in the recreational one (resp. $5.06 \mathrm{mmol} / \mathrm{l}$ vs. $7.16 \mathrm{mmol} / \mathrm{l} ; P=0.03$ and 5.86 $\mathrm{mmol} / \mathrm{l}$ vs. $7.82 \mathrm{mmol} / \mathrm{l} ; P=0.04$ ) (Figure 1).

The Bravais - Pearson correlation coefficient between muscular power and $\mathrm{VO}_{2} \max$ determined by Cooper test indicates a positive link between both muscular power and endurance qualities in the competitive group $(\mathrm{r}=0.80 ; 0.51$ - 0.93) whereas no link could distinguish the recreational group $(\mathrm{r}=-0.06 ;-0.54-0.44)$. Moreover, the Bravais Pearson correlation coefficient between muscular power and mean value of maximal speed determined with the specific Fencing Endurance Test indicates a positive link between both muscular power and endurance qualities in the competitive group in an ecological way of practice $(r=0.84$; $0.60-0.94)$ as opposed to the recreational group $(\mathrm{r}=0.24$; - 0. 29 - 0.66). On the contrary, the Bravais - Pearson correlation coefficient between muscular power and the mean value of maximal heart rates determined with the specific Fencing Endurance Test does not indicate any link between both muscular power and maximal heart rates in competitive and in recreational groups (resp. $\mathrm{r}=-0.57 ;-0.82--0.08$ and $\mathrm{r}=-0.07$; $0.55-0.44)$ (Figure 2).

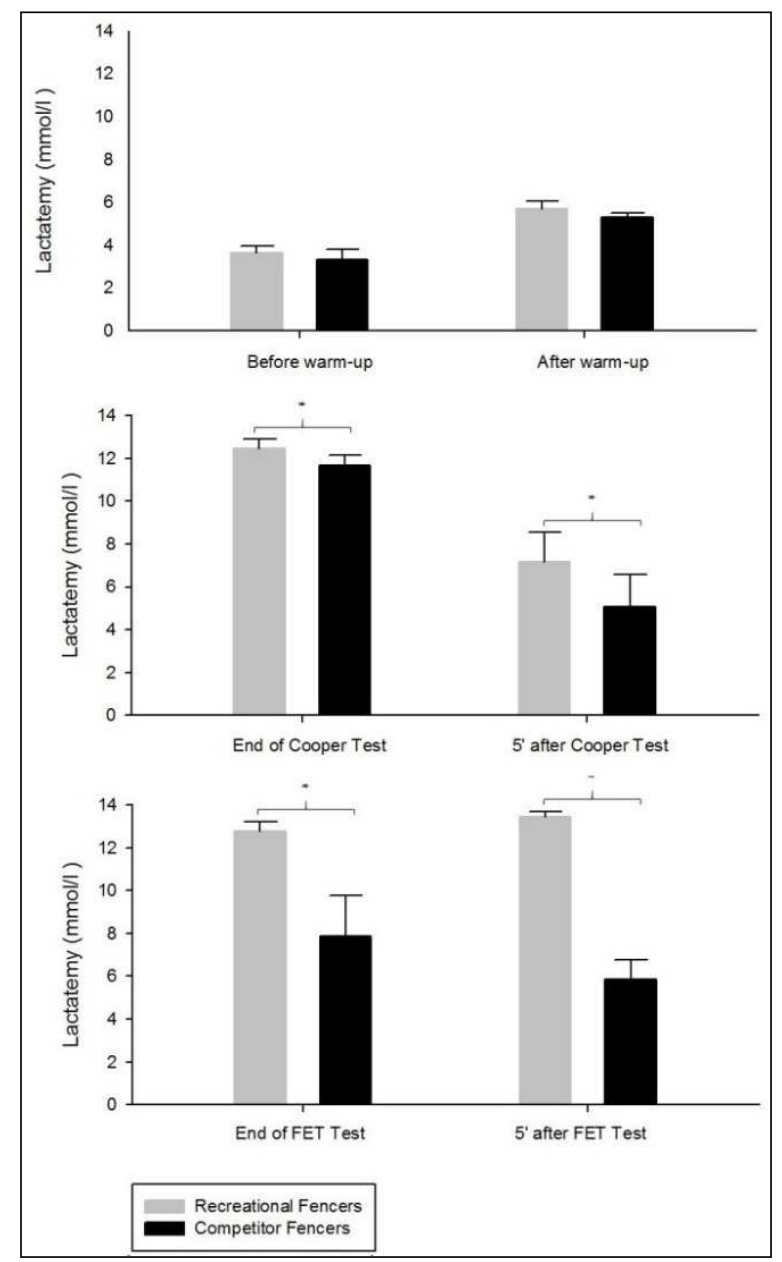

Figure 1. Blood lactate concentration before and after warm-up, at the end and 5 ' after Cooper test and at the end and 5 ' after FET. (*: significant main effect). 


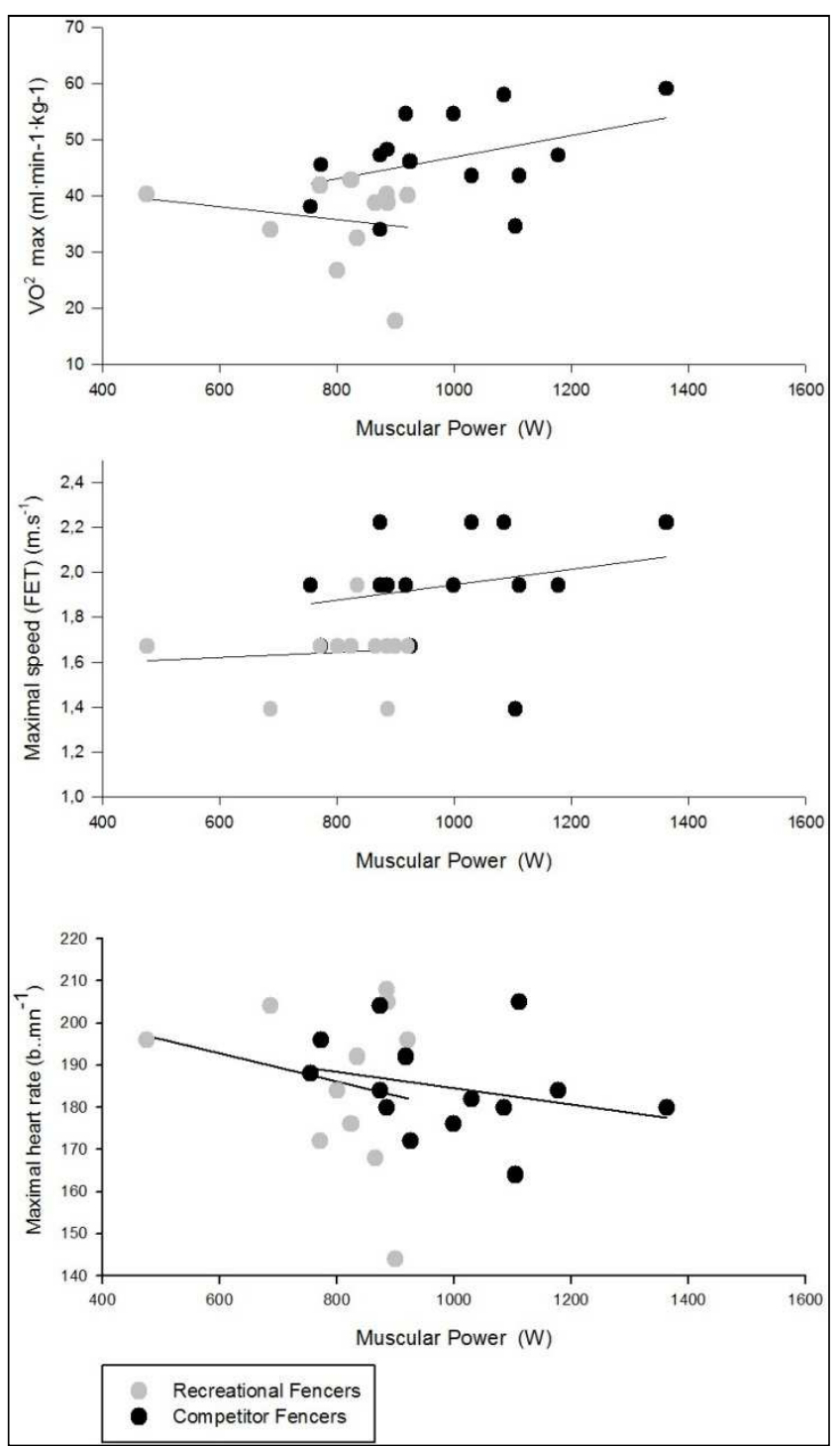

Figure 2. Linear Correlation between Muscular Power and (from top to bottom) $\mathrm{VO}_{2}$ max, Mean Value of Maximal Speed (FET) and Maximal Heart Rate.

\section{Discussion}

Fencing is a combat sport which can be studied at different levels particularly as regards to the metabolic processes involved. Although aerobic processes allow to compete and to hold a series of bouts, phosphocreatine processes allow to face specific sequences during a bout. The aim of this study was to search for a possible correlation between these two processes in young fencers involved in competition and in young recreational fencers. These processes were studied through basic field tests and through a specific fencing endurance test.

The main result of this study is the fact that competitors present both higher aerobic endurance capacity (expressing aerobic process) and higher anaerobic alactic capacity (expressing phosphocreatine process) than recreational fencers. Despite deep differences between these two processes providing energy for muscular activity, whether it be about the oxygen uptake or about the intensity of exercise
[4], competitors reach high level for both. Whatever the endurance test used, competitors have the highest $\mathrm{VO}_{2} \max$ level and they reach the highest speed steps during the FET. So, the capability to perform an intensive effort during a long time does not impair the capability to produce a highly explosive exercise in young fencers involved in competition. The coefficient of correlation confirms the strong link between these qualities. Our results in young fencers confirm Nystrom et al. [14], who indicate that both aerobic and dynamic strength are present collectively in world class fencers. So, following these results, physiological needs have to be, necessarily, considered in two temporal scales, one based on competition duration and one based on bout duration.

The lack of correlation between the levels of aerobic endurance capacity and muscular power in young recreational fencers indicates that both capacities are necessary but not necessarily jointly. It tends to confirm that the association between both aerobic endurance capacity and muscular power is the main element of competitiveness. These results are in line with Harris et al. [15] whose work indicates that the synthesis of phosphocreatine requires necessarily the presence of oxygen. Physiologically, these two qualities are complementary despite their differences in terms of oxygen uptake.

The specificity of fencing is highlighted by the analysis of heart rate measures. Beyond energy muscular furniture, the activity is conditioned by the stake of combat which incites fencers to reach higher heart rates, whatever their sport level [16]. The maximum heart rates between young competitors and young recreational fencers recorded in the unspecific Cooper test are lower than the maximum heart rates recorded in FET. Moreover, the maximum heart rates between young competitor and recreational fencers recorded in the unspecific Cooper test are significantly different for each group whereas the maximum heart rates recorded in FET cannot distinguish young competitors and recreational fencers. These latter values are significantly higher in both Competitors and Recreational groups than the ones recorded in Cooper test. The duration of effort and duration of each step ( $3 \mathrm{~min}$.), showed by the speed step reached, suggests the fact that young fencers could use the glycolysis - lactic acid process in higher steps of test. Their capability to reach these steps seems to represent their tolerance of high - intensity exercise. Finally, the capability to sustain high heart rate allows to face the requirements of the fencing movements permitting to lower total response time and accuracy of movement despite fatigue $[6,17]$. The average blood lactate concentration shows evidence of these assertions. It confirms the capability of young fencers (especially competitors after the specific Fencing Endurance Test) to sustain high levels of exercise, particularly in fencing specific displacements [18]. The average blood lactate concentration clearly indicates that the glycolysis - lactic acid process is used to generate ATP for muscle activity [19].

These results raise questions about training and the self perception of effort. Whereas the aerobic and phosphocreatine 
processes seem necessary to succeed in fencing, our results suggest the necessity to integrate both processes while training. The combined development of different training modalities allows to develop combined effects of concurrent strength and endurance training. It has been studied for a long time [20]. The effects of concurrent strength and endurance training, involved in the development of both aerobic and phosphocreatine systems, had particularly been studied with a lack of unanimous conclusions. The association of such different modalities seems to show negative effects particularly to the detriment of strength modality [21 - 23]. Hickson et al. [21] particularly indicated that muscular power is altered when simultaneous training in aerobic and strength modalities. Moreover, it seems there is evidence that endurance training inhibits maximal strength development [24]. However, strength training does not interfere with the development of the maximal oxygen uptake [25]. Because endurance training reduces fat mass, our results confirm that competitors have also a better level of strength and endurance.

Moreover, following Weichenberger et al. [11], a specific test appears to be more accurate to represent the physiological load of fencing [26]. In such ecological test conditions, cognitive and psychological aspects influence physiological behavior. So, the lack of specificity of the muscular power test could be considered as the main limit of this study. An unspecific test appears to be more accurate to study a physiological quality isolated from the specific task constraints. However, beyond these precisions, specific and unspecific tests allow to distinguish the same hierarchy between fencers independently of heart rate measure which does not appear to be the most pertinent variable.

\section{Practical Applications}

The present study confirms that fencing in competition requires both phosphocreatine and aerobic processes to produce ATP. It tends to question physical training methods usually used in fencing which consider endurance as the main physical quality to develop whether it be for young or adult fencers, whether it be for competitor or recreational fencers. Moreover, one could be surprised at the high intensity activity which can evoque possibility to use the glycolysis process which produces ATP without oxygen, producing lactic acid in muscles and blood. An experiment allowing to study this possibility should be planned.

\section{Acknowledgements}

The author is particularly grateful for the assistance given by Anne Alibert (Institut National Polytechnique, Toulouse, France).

\section{References}

[1] Lavoie J - M, Leger LA, Pitre R. Compétitions d'escrime: épée. Analyse des durées et distances de déplacement. Médecine du Sport. 1985; 59: 279 - 83.
[2] Roi GS, Bianchedi D. The Science of Fencing. Implications for Performance and Injury Prevention. Sports Medicine. 2008; 38: $466-81$.

[3] Bottoms LM, Sinclair J, Gabrysz T, Szmatlan - Gabrysz U, Price MJ. Physiological responses and energy expenditure to simulated epee fencing in elite female fencers. Serbian Journal of Sports Sciences. 2011; 5: 17 - 20.

[4] Astrand P - O, Rodahl K, Dahl HA, Stromme SB. Textbook of Work Physiology: Physiological Bases of Exercise (4th ed.). Champaign (Il): Human Kinetics Publishers; 2003.

[5] Turner A, Miller S, Stewart P, Cree J, Ingram R, Dimitriou L, et al. Strength and Conditioning for Fencing. Strength and Conditioning Journal. 2013; 35: 1 - 9.

[6] Hüttermann S, Memmert D. Does the inverted - U function disappear in expert athletes? An analysis of the attentional behavior under physical exercise of athletes and non - athletes. Physiology \& Behavior. 2014; 131: 87 - 92.

[7] Kamal Hijazi MM. Attention, Visual Perception and their Relationship to Sport Performance in Fencing. Journal of Human Kinetics. 2013; 39: 195 - 201.

[8] Sargent DA. The physical test of a man. American Physical Education Review. 1921; 26: 188 - 94.

[9] Fox EL, Mathews DK. Interval Training: Conditioning for Sports and General Fitness. Philadelphia: W. B. Saunders; 1974.

[10] Cooper KH. A means of assessing maximal oxygen intake. Correlation between field and treadmill testing. The Journal of American Medical Association. 1968; 203: 201 - 4.

[11] Weichenberger M, Liu Y, Steinacker JM. A Test for Determining Endurance Capacity in Fencers. International Journal of Sports Medicine. 2012; 33: 48 - 52.

[12] Durnin JVG, Rahaman MM. The assessment of the amount of fat in the human body from measurements of skinfold thickness. British Journal of Nutrition. 1967; 21: 681 - 9.

[13] Fischer RA, Yates F. Statistical Tables For Biological, Agricultural And Medical Research. Edinburgh: Oliver and Boyd; 1975.

[14] Nystrom J, Lindwall O, Geci R, Harmenberg J, Swedenhag J, Ekblom B. Physiological and morphological characteristics of world class fencers. International Journal of Sports Medicine. 1990; 11: $136-9$.

[15] Harris R, Edwards R, Hultman E, Nordesjö L, Nylind B, Sahlin K. The time course of phosphorylcreatine resynthesis during recovery of the quadriceps muscle in man. Pflugers Archive. 1976; 367: 137 - 42.

[16] Stewart KJ, Peredo AR, Williams CM. Physiological and morphological factors associated with successful fencing performance. Journal of Human Ergology (Tokyo). 1977; 6: $53-60$.

[17] Williams LRT, Walmsley A. Response timing and muscular coordination in fencing: A comparison of elite and novice fencers. Journal of Science and Medicine in Sport. 2000; 3: $460-75$.

[18] Guellich A, Seiler S. Lactate Profile Changes in Relation to Training Characteristics in Junior Elite Cyclists. International Journal of Sports Physiology and Performance. 2010; 5: 316 - 27. 
[19] Housh TJ, Devries HA, Housh DJ, Tichy MW, Smyth KD, Tichy AM. The relationship between critical power and the onset of blood lactate accumulation. Journal of Sports Medicine and Physical Fitness. 1991; 31:31 - 6.

[20] Verkhoshansky Y. Main Features of a Modern Scientific Sports Training Theory. New Studies in Athletics. 1998; 3: 21 - 31.

[21] Hickson RC, Rosenkoetter MA, Brown MM. Strength training effects on aerobic power and short - term endurance. Medicine \& Science in Sports \& Exercise. 1980; 12: 336 - 9.

[22] Kenney WL, Wilmore JH, Costill DL. Physiology of Sport and Exercise. Champaign (Il): Human Kinetics Publishers; 2011.

[23] Nelson AG, Arnall DA, Loy SF, Silvester LJ, Conlee RK.
Consequences of combining strength and endurance training regimens. Physical Therapy. 1990; 70: 287 - 94.

[24] Sale DG, McDougall JD, Jacobs I, Garner S. Interaction between concurrent strength and endurance training. Journal of Applied Physiology. 1990; 68: 260 - 70.

[25] Millet GP, Jaouen B, Borrani F, Candau R. Effects of concurrent endurance and strength training on running economy and VO2 kinetics. Medicine \& Science in Sports \& Exercise. 2002; 34: 1351 - 9.

[26] Tsolakis C, Bogdanis GC, Nikolaou A, Zacharogiannis E. Influence of type of muscle contraction and gender on postactivation potentiation of upper and lower limb explosive performance in elite fencers. Journal of Sports Science and Medicine. 2011; 10: 577 - 83. 